\title{
Influence of virtual reality on postural balance and quality of life of pregnant women: controlled clinical trial randomized
}

\author{
Influência da realidade virtual no equilíbrio postural e qualidade de \\ vida de mulheres grávidas: ensaio clínico controlado randomizado
}

\author{
Silvia Oliveira Ribeiro, Vanessa Patrícia Soares de Sousa, Elizabel de Souza Ramalho Viana*
}

Universidade Federal do Rio Grande do Norte (UFRN), Natal, RN, Brazil

\begin{abstract}
Introduction: During pregnancy women undergo several transformations, which promote changes in their gravity center (GC) and can result in postural and balance changes. Objective: To evaluate the influence of Nintendo WiiFit Plus ${ }^{\circledR}$ on postural balance and quality of life of pregnant women in the third trimester. Methods: 250 pregnant women enrolled through a non-probabilistic sampling process. The sample consisted of 32 women selected according to the eligibility criteria (nulliparity; low-risk pregnancy, absence of musculoskeletal disorders or surgical procedures in the spine, pelvis, hip or knee), musculoskeletal disorders, allocated as follows: 17 pregnant women in the control group (CG) and 15 pregnant women in the experimental group (EG). The intervention was performed in 12 sessions of 30 minutes each, three times a week. Sociodemographic and obstetric data were presented as median and interquartile range (25\% - 75\%). A comparison of the relative values of variables before and after the exercise program was performed using the $2 \times 2$ ANOVA test $(5 \%$ significance level). Results: There were no significant statistical differences in variables related to postural balance $(\mathrm{P}>0.06)$ and quality of life $(\mathrm{P}>0.13)$. Conclusion: The use of Nintendo WiiFit Plus games was not able to promote improvement in postural balance and quality of life of the pregnant women studied.
\end{abstract}

Keywords: Rehabilitation. Pregnancy. Physiotherapy. Postural Balance. Video Games.

\footnotetext{
* SOR: MS, e-mail: oliveira.silviaribeiro@gmail.com

VPSS: Doctoral student, e-mail: vanessafisio@gmail.com

ESRV: PhD, e-mail: elizabelviana@gmail.com
} 
Resumo

\begin{abstract}
Introdução: Durante a gravidez as mulheres passam por várias transformações, que promovem mudanças no seu centro de gravidade (CG) e pode resultar em alterações posturais e de equilíbrio. Objetivo: Avaliar a influência da Nintendo Wii Fit Plus ${ }^{\circledR}$ no equilíbrio postural e qualidade de vida das mulheres grávidas no terceiro trimestre. Métodos: 250 gestantes cadastradas através de um processo de amostragem do tipo não-probabilística. A amostra foi composta por 32 mulheres selecionadas de acordo com os critérios de elegibilidade (nuliparas, gestação de baixo risco, ausência de disfunções musculoesqueléticas ou cirurgia na coluna vertebral, pelve, quadril ou joelho) alocadas da seguinte maneira: 17 gestantes no grupo controle (GC) e 15 gestantes no grupo experimental (GE). A intervenção foi realizada em 12 sessões de 30 minutos cada, três vezes por semana. Os dados sociodemográficos e obstétricos foram apresentados como mediana e interquartil (25\% - 75\%). Uma comparação entre os valores relativos das variáveis antes e depois do programa de exercícios foi realizada utilizando o teste ANOVA 2x2 (nível de significância de 5\%). Resultados: A mediana gestacional e idade cronológica foram, respectivamente, 30,50 (27,2 - 32,0) anos e 28,5 (27,7 - 30,0) semanas. Não houve diferenças estatisticamente significativas nas variáveis relacionadas ao equilíbrio postural $(P>0,06)$ e qualidade de vida $(P>0,13)$. Conclusões: $O$ uso de jogos Nintendo Wii Fit Plus não foi capaz de promover a melhora no equilíbrio e qualidade de vida das gestantes estudadas postural.
\end{abstract}

Palavras-chave: Reabilitação. Gravidez. Fisioterapia. Equilíbrio Postural. Jogos de Vídeo.

\section{Introduction}

Postural balance is obtained by the sum of all forces and momentum of force acting on the body, resulting in zero (1). For better balance, the individual seeks to keep its body mass center within their limits of stability, which is determined by the ability to control posture without changing the support base (2). The maintenance of postural balance is attributed to postural control, which refers to the functions of sensory, visual and vestibular systems, mediated by the central nervous system (CNS) $(1,3)$.

During pregnancy, women undergo several transformations (4), which promote changes in their gravity center $(\mathrm{GC})(5,6)$. Anterior and superior shifting $(5,7)$ result in postural and balance changes $(8,9)$, and may contribute to postural instability, leading to a higher incidence of falls (10 - 12). In this perspective, it becomes clear that pregnant women are subjected to several predictors of important bodily changes which are able to reflect directly on their quality of life (13).

Nintendo Wii ${ }^{\circledR}$ is an exergame (14), created in 2006 based on the concepts of virtual reality (VR) (15), and is a resource capable of enhancing visual biofeedback $(2,16)$ serving, among other benefits, as a therapeutic tool in correcting posture and balance (17-19). In addition, this device seems to be a useful tool for maximizing quality of life, as it provides high levels of physical interaction, making therapy more pleasant and with greater individual involvement (18). However, there is lack of research using game therapy as a physiotherapy intervention tool in populations of pregnant women. Thus, the aim of this study was to investigate the influence of using Nintendo Wii Fit Plus ${ }^{\circledR}$ on postural balance and quality of life of pregnant women. We hypothesized that the proposed exercise protocol would improve the variables related to postural balance and quality of life in the studied sample.

\section{Methods}

This is a controlled experimental research developed at the Laboratory of Maternal and Child Care Department of Physical Therapy, Federal University of Rio Grande do Norte - UFRN. The research was submitted to the Human Research Ethics Committee of UFRN, approved under protocol number 719.939 and submitted to the BrazilianClinicalTrials Registry under protocol number RBR - 4j35g5. Volunteers signed the Clear and Informed Consent Form according to the regulations of Resolution 466/12 of the National Health Council. 
This study is part of a larger research that proposes to investigate the effect of virtual reality on different variables in the pregnant population. For this article, only women who were in the third trimester of pregnancy were selected to analyze whether the proposed protocol would have any influence on the postural balance and quality of life of women who were already submitted to various adaptations due to pregnancy.

The study population consisted of women in the third gestational trimester (between 27 and 37 weeks), residents of the city of Natal-RN and participants of the Preparatory Course for Pregnancy, Childbirth and Postpartum (PCPCP), promoted by the Department of Physical Therapy, UFRN. There was a total of 250 enrollments in the study period, through a non-probabilistic convenience sampling process. The randomization process was carried out electronically via the website http://www.randomization.com. The two pieces of information included were: sample size and number of groups. With this data, the site generated a specific coding for each group and randomly distributed the subjects. Our sample consisted of 32 women selected according to the eligibility criteria, allocated as follows: 17 pregnant women in the control group (CG) and 15 pregnant women in the experimental group (EG).

The inclusion criteria established were: Nulliparity; low-risk pregnancy (not presenting risk of miscarriage, twin pregnancy, hypertension induced by high-risk pregnancy, gravidicchanges such as pregnancy toxemia, severe anemia, placenta previaand gestational diabetes); being aged between 18 and 35 years; not smok or use alcohol and illicit drugs; being in the third trimester of pregnancy (between 27-37 weeks); absence of: vestibulopathy and bone injuries in the last five years, which could interfere in balance, surgical procedures in the spine, pelvis, hip or knee, musculoskeletal disorders, use of anti-inflammatory drugs and/or analgesics that affect balance.

Exclusion criteria were women who had any obstetric or musculoskeletal changes during the study period (such as cramps, bleeding, placental abruption, heel pain or low back pain) and those who were absent for three (consecutive or not) game therapy sessions.
Evaluation Protocol

All participants underwent the following evaluation protocol:

1) Evaluation Form, through which demographic, clinical, anthropometric and obstetric information were obtained from the sample;

2) Ferrans and Powers Quality of Life Index, a specific questionnaire to assess quality of life in pregnant women. It consists of 72 questions divided into two parts: Satisfaction and Importance. It features five domains: health and functioning, socioeconomic, psychological, spiritual and family. The total score and domains range from 0 to 30 , with scores closer to 30 indicating a better quality of life (20).

3) Postural balance assessment through the Balance MasterSystem ${ }^{\circledR}$. Four tests were selected: Modified Clinical Test of Sensory Interaction on Balance (mCTSiB), Rhythmic Weight Shift Test (RWS) and Sit to stand (STS).

In the mCTSIB, the oscillation speed was measured in four different situations: 1) Eyes open on a stable surface; 2) Eyes closed on a stable surface; 3) Eyes open on an unstable surface; and 4) Eyes closed on an unstable surface. Dynamic balance was testedfor the RWS in order to obtain oscillation speed and directional control during the execution of two movements: lateral-lateral and antero-posterior at three speeds: slow, medium and fast. STS was conducted upon request that women stand up from a sitting position.

The assessments were performed in the afternoon, respecting circadian rhythm and reducing its influence on the studied variables (21).

\section{Intervention protocol}

The intervention with the virtual reality program was developed in twelve (12) sessions lasting thirty (30) minutes, not including rest time which was about 2 minutes rest after each game. The frequency was three (3) times per week for a period of four (4) weeks. All participants were instructed not to do the Nintendo Wii Fit Plus ${ }^{\circledR}$ balance exercises at home.

Individual sessions were conducted with a Wii balance board ${ }^{\circledR}(\mathrm{WBB})$, recently validated as a strength platform (16) and as an instrument for equilibrium analysis in the orthostatic position (2). 
In the virtual training environment there was a television connected to a Wii console, equipped with sensors responsible for obtaining the data sent by the balance board and controls via wireless transfer. The balance board was placed directly on the floor at a distance of 2.4 meters from the TV; a physiotherapist was constantly positioned next to the volunteer, being responsible for providing guidance and monitoring the participant throughout the duration of the intervention.

The Wii Fit Plus ${ }^{\circledR}$ package games used for the balance training were: Balance bubble, Tightrope, Ski jump, Penguin slide and Soccer heading. All participants engaged in five games in the order described above, with designated time of 4 minutes for each set, corresponding to approximately to two cycles. Before starting the protocol, the volunteers had one familiarization session with the games. At the end of the last session, all patients were reassessed, and once again subjected to the initial assessment protocol.

Assessment, intervention and analysis of data procedures were conducted by distinct and trained researchers.

For a better understanding of the methodology, the steps of this study are shown in Figure 1.

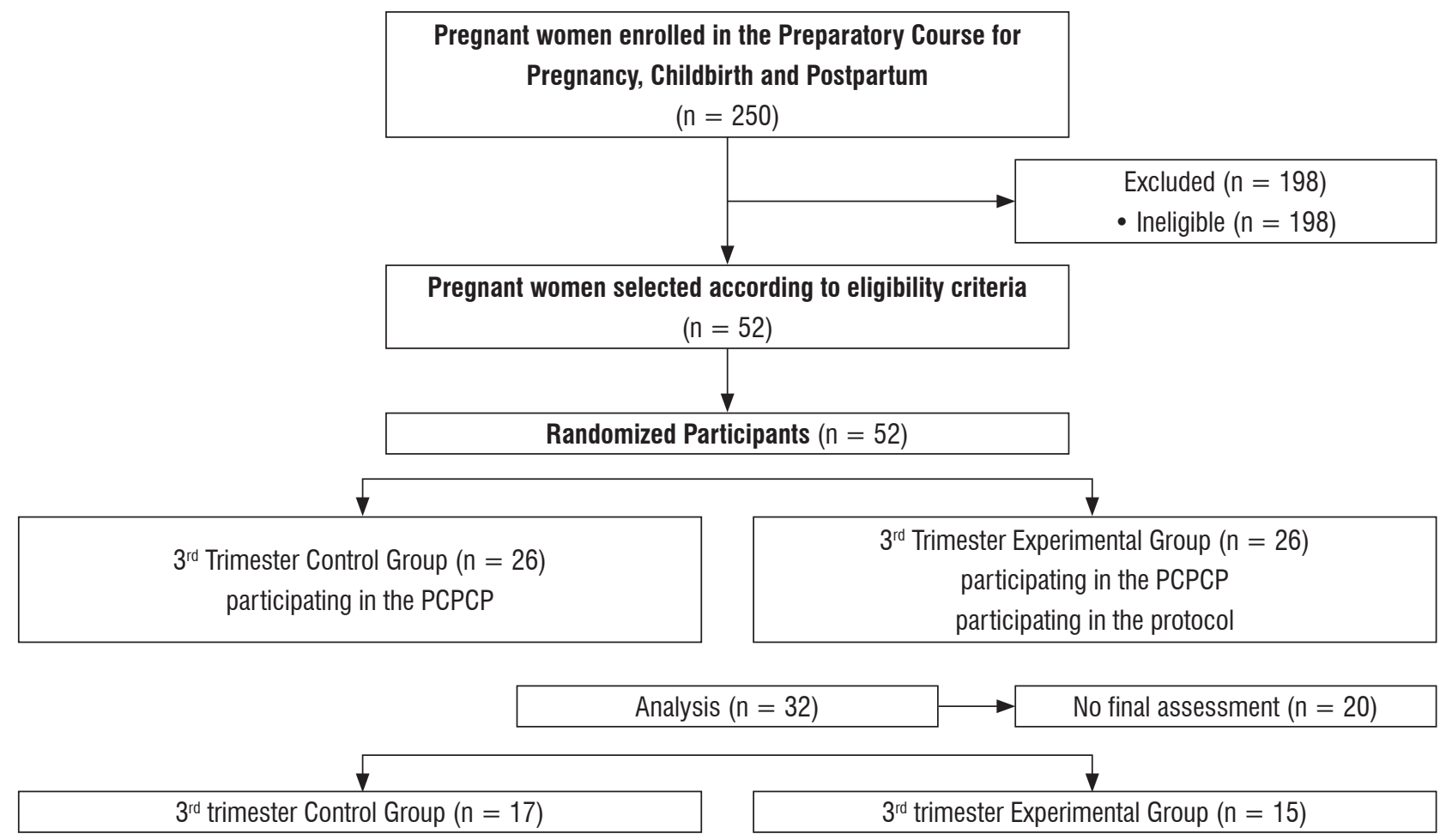

Figure $\mathbf{l}$ - Study distribution flowchart according to CONSORT.

Statistical analysis

Statistical analysis was performed using SPSS (version 20.0). The Shapiro-Wilk test was used to verify the normality of quantitative variables. A descriptive analysis regarding sociodemographic, obstetric, anthropometric was conducted in order to characterize the sample. It was used 2x2 ANOVA test for repeated measurements to compare the varying outcomes of this study, before and after the intervention with the Nintendo Wii Fit Plus ${ }^{\circledR}$ games. Statistical significance of $\mathrm{p}<0.05$ was considered.

\section{Results}

The characterization of the sample with respect to sociodemographic, obstetric and anthropometric variables at the time of initial evaluation is shown in Table 1. 
Table 1 - Sample characterization

\begin{tabular}{lcc}
\hline Variables & 3TCG $(\mathbf{n}=\mathbf{1 7})$ & 3TEG $(\mathbf{n}=\mathbf{1 5})$ \\
\hline Sociodemographic data & & \\
$\quad$ Age (in years) & $29.58 \pm 3.83$ & $29.53 \pm 3.15$ \\
$\quad$ Education (in years) & $15.55 \pm 1.67$ & $15.46 \pm 1.27$ \\
Marital status & $70.6 \%(12)$ & \\
$\quad$ Married & $29.4 \%(5)$ & $80 \%(12)$ \\
$\quad$ Has a companion & - & $13.3 \%(2)$ \\
$\quad$ Does not have a companion & & $6.7 \%(1)$ \\
Obstetric data & $27.76 \pm 3.19$ & $26.93 \pm 4.49$ \\
$\quad$ GA(in weeks) average & & \\
Anthropometric data & $59.75 \pm 14.66$ & $64.08 \pm 10.95$ \\
$\quad$ Weight (in Kg) & $1.60 \pm 0.05$ & $1.62 \pm 0.06$ \\
$\quad$ Height (in Meters) & &
\end{tabular}

During the subjective assessment of postural balance, $28.1 \%(n=9)$ of the women reported noticing changes in this function after pregnancy. When asked about the decrease in the balance when performing activities of daily living like getting dressed or doing household activities, 46.9\% $(n=15)$ said they had noticed a change in postural balance.

An inferential statistical analysis was performed in order to detect possible effects of Wii-rehabilitation protocol on postural balance and quality of life in the sample. Considering the two time points, statistically significant differences were only found in the intragroup conditions for the OSLL (Oscillation speed during latero-lateral movement) condition of postural balance.

For the other variables, there were no statistically significant intragroup and intergroup differences (SSEO - Oscillation speed on a stable surface with eyes open - intragroup [ $\mathrm{F}=3.02 \mathrm{p}=0.09]$; intergroup $[\mathrm{F}=0.02 ; \mathrm{p}=0.88]$; SSEC - Oscillation speed on a stable surface with eyes closed - intragroup $[\mathrm{F}=0.91 \mathrm{p}=0.34]$; intergroup $[\mathrm{F}=0.03 ; \mathrm{p}=0.84]$; SUEO - Oscillation speed on an unstable surface with eyes open - intragroup [ $\mathrm{F}=0.21 \mathrm{p}=0.65]$; intergroup [F = 0.21; $p=0.65]$; SUEC - Oscillation speed on an unstable surface with eyes closed intragroup $[F=0.03 p=0.84]$; intergroup $[F=0.61$ $\mathrm{p}=0.43]$; OSLL - Oscillation speed during laterolateral movement - intragroup $[F=5.83 p=0.02]$; intergroup [F $=0.07 \mathrm{p}=0.93]$; OSAP - Oscillation speed during antero-posterior movement intragroup $[\mathrm{F}=3.31 \mathrm{p}=0.07]$; intergroup $[\mathrm{F}=2.56$ $\mathrm{p}=0.12]$; DCLL - Directional control during laterolateral movement - intragroup $[F=1.71 p=0.20]$; intergroup $[F=1.59 p=0.21]$; DCAP - Directional control during antero-posterior movement intragroup $[\mathrm{F}=0.47 \mathrm{p}=0.49]$; intergroup $[\mathrm{F}=0.81$ $\mathrm{p}=0.37]$; $\mathrm{TT}$ - Transfer time - intragroup $[\mathrm{F}=0.782$ $\mathrm{p}=0.382]$; intergroup $[\mathrm{F}=0.611 \mathrm{p}=0.612]$; $\mathbf{S R}$ Standing Ratio - intragroup $[F=0.16 p=0.69]$; intergroup $[F=0.17 p=0.67] ; \mathbf{V}$ - intragroup $[F=0.00$ $\mathrm{p}=0.98]$; intergroup $[\mathrm{F}=0.29 \mathrm{p}=0.59]$; WSLR Weight symmetry between right and left lower limbs - intragroup [ $F=0.18 p=0.66]$; intergroup $[F=0.14 p=0.71] ;$ Total - intragroup $[F=0.19$ $\mathrm{P}=0.66]$; intergroup $[\mathrm{F}=1.89 \mathrm{P}=0.17]$; Health and Functioning - intragroup $[\mathrm{F}=0.16 \mathrm{P}=0.68]$; intergroup $[\mathrm{F}=2.06 \mathrm{P}=0.16$ ]; Socioeconimic intragroup $[\mathrm{F}=1.18 \mathrm{P}=0.28]$; intergroup $[\mathrm{F}=1.32$ $\mathrm{P}=0.25]$; Psychological and Spiritual - intragroup $[\mathrm{F}=1.74 \mathrm{P}=0.19]$; intergroup $[\mathrm{F}=3.21 \mathrm{P}=0.08]$; Family - intragroup $[\mathrm{F}=1.56 \mathrm{P}=0.22]$; intergroup $[\mathrm{F}=3.73 \mathrm{P}=0.06])$. The results of this analysis are shown in Table 2. 
Table 2 - Intra and inter-group interaction analysis of postural balance and quality of life variables between initial and final assessment conditions

\begin{tabular}{|c|c|c|c|c|c|c|}
\hline & \multicolumn{2}{|c|}{ Before } & \multicolumn{2}{|c|}{ After } & \multicolumn{2}{|c|}{$\begin{array}{l}\text { 95\% Confidence } \\
\text { Interval }\end{array}$} \\
\hline & $\begin{array}{c}\text { CG } \\
\text { participants }\end{array}$ & $\begin{array}{c}\text { EG } \\
\text { participants }\end{array}$ & $\begin{array}{c}\text { CG } \\
\text { participants }\end{array}$ & $\begin{array}{c}\text { EG } \\
\text { participants }\end{array}$ & $\begin{array}{l}\text { Lower } \\
\text { bound }\end{array}$ & $\begin{array}{l}\text { Upper } \\
\text { bound }\end{array}$ \\
\hline \multicolumn{7}{|l|}{ MCTSB } \\
\hline SSEO (in \%s) & $0.33 \pm 0.09$ & $0.27 \pm 0.12$ & $0.29 \pm 0.09$ & $0.23 \pm 0.07$ & 0.258 & 0.307 \\
\hline SSEC (in \%s) & $0.32 \pm 0.12$ & $0.29 \pm 0.09$ & $0.31 \pm 0.13$ & $0.26 \pm 0.10$ & 0.265 & 0.336 \\
\hline SUEO (in \%s) & $0.48 \pm 0.19$ & $0.39 \pm 0.14$ & $0.52 \pm 0.23$ & $0.39 \pm 0.15$ & 0.393 & 0.505 \\
\hline SUEC (in \%) & $0.80 \pm 0.38$ & $0.73 \pm 0.58$ & $0.90 \pm 0.54$ & $0.67 \pm 0.33$ & 0.644 & 0.916 \\
\hline \multicolumn{7}{|l|}{ Rhythmic weight shift test } \\
\hline OSLL(in $\%$ s) & $4.52 \pm 0.31$ & $4.45 \pm 0.88$ & $4.85 \pm 0.78$ & $4.80 \pm 0.74$ & 4.40 & 4.91 \\
\hline OSAP(in \%s) & $2.83 \pm 0.36$ & $3.29 \pm 1.38$ & $2.79 \pm 0.44$ & $2.65 \pm 0.37$ & 2.69 & 3.09 \\
\hline DCLL(in \%) & $80.94 \pm 3.91$ & $73.81 \pm 20.64$ & $74.17 \pm 6.55$ & $80.13 \pm 5.34$ & 77.99 & 81.97 \\
\hline DCAP(in \%) & $76.88 \pm 6.68$ & $71.26 \pm 8.02$ & $6.23 \pm 4.88$ & $70.66 \pm 7.19$ & 70.96 & 75.53 \\
\hline \multicolumn{7}{|l|}{ STS } \\
\hline TT (in s) & $0.47 \pm 0.18$ & $0.77 \pm 0.72$ & $0.49 \pm 0.19$ & $0.64 \pm 0.36$ & 0.470 & 0.721 \\
\hline RS (in \%) & $12.47 \pm 4.57$ & $13.38 \pm 8.71$ & $11.47 \pm 3.04$ & $13.40 \pm 2.38$ & 11.26 & 14.09 \\
\hline$V($ in $\%$ s) & $3.31 \pm 1.07$ & $3.10 \pm 1.13$ & $3.44 \pm 0.78$ & $2.97 \pm 1.03$ & 2.940 & 3.477 \\
\hline WSLR (in\%) & $6.23 \pm 4.88$ & $8.73 \pm 6.09$ & $5.29 \pm 5.53$ & $8.66 \pm 7.33$ & 5.427 & 9.037 \\
\hline \multicolumn{7}{|l|}{ Quality of life ${ }^{c}$} \\
\hline Total & $22.89 \pm 2.61$ & $23.63 \pm 3.19$ & $24.17 \pm 3.51$ & $22.97 \pm 4.58$ & 22.36 & 24.47 \\
\hline Health and Functioning & $21.17 \pm 3.65$ & $22.81 \pm 3.02$ & $21.90 \pm 2.05$ & $21.48 \pm 3.22$ & 20.97 & 22.71 \\
\hline Socioeconomical & $22.51 \pm 2.54$ & $23.03 \pm 3.13$ & $22.54 \pm 1.94$ & $21.82 \pm 3.74$ & 21.59 & 23.36 \\
\hline Psychological and Spiritual & $24.78 \pm 2.80$ & $24.87 \pm 3.85$ & $25.03 \pm 2.82$ & $23.19 \pm 3.95$ & 23.38 & 25.55 \\
\hline Family & $24.77 \pm 4.13$ & $25.27 \pm 4.19$ & $25.30 \pm 3.61$ & $22.81 \pm 4.37$ & 23.30 & 25.79 \\
\hline
\end{tabular}

Note: SSEO - Oscillation speed (deg/sec) on a stable surface with eyes open; SSEC - Oscillation speed (deg/sec) on a stable surface with eyes closed; SUEO - Oscillation speed (deg/sec) on an unstable surface with eyes open; SUEC - Oscillation speed (deg/sec) on an unstable surface with eyes closed; OSLL - Oscillation speed during latero-lateral movement; OSAP - Oscillation speed during antero-posterior movement; DCLL - Directional control (in \%) during latero-lateral movement; DCAP - Directional control (in \%) during antero-posterior movement; TT - Transfer time (in seconds); SR - Standing Ratio (in \%); WSLR - Weight symmetry between right and left lower limbs. $\square$ Statistically significant intra-group interaction $(F=5.83 P=0.02)$ c Ferrans and Powers Quality of Life Index values.

\section{Discussion}

Changes in the GC leads to changes in body alignment which can affect postural balance and may directly reflect in pregnant women's quality of life (14). In our study, no statistically significant differences were observed in the analyzed variables after the training sessions, except for OSLL Oscillation speed during latero-lateral movement (F $=5.83 ; \mathrm{p}=0.02$ ) in the intragroup condition.

The results of this study showed that $28.1 \%$ of women reported observing changes in balance during pregnancy, while $46.9 \%$ found it difficult to carry out any activity of daily living. During pregnancy, load increases and so does the imbalance in the joint system, especially in the third trimester (22) due to the increase of body weight (6), which can cause disturbance in the GC and a greater oscillation of the center of force (CF) (21), which can affect postural balance $(4,21)$.

Previous studies have found that women in the first trimester show changes in postural control and, with advancing pregnancy, there is a tendency of reduced postural stability. This decrease occurs 
due to an anterior shifting of the gravity center (GC) and increased body weight, thereby increasing the susceptibility of postural instability in women in the third gestational trimester $(22,23)$.

For Inanir et al. (10), progressive weight gain that occurs during the first trimester, would explain the preservation of postural stability found in women during this period. In contrast, a substantial weight gain rate in the third quarter justify the decrease of postural balance that stage. However, Butler et al. (24) found that the decrease in postural balance of pregnant women in the second and third trimester compared to non-pregnant women and the persistence of this framework in the post-partum period, showed no correlation between the balance and weight gain. This suggests that postural stability in this population would be more related to hormonal changes, ligament and joint than the increase in the abdomen or weight gain $(4,24)$.

Thus, a static and dynamic posture evaluation during pregnancy may contribute to the development and application of therapeutic methods that prevent instability and falls during pregnancy $(25,26)$, by avoiding tasks of large risks.

This study found that oscillation speed during lateral-lateral movement in the time axis/factor showed a statistically significant difference, suggesting that participants achieved a better gravity center (GC) oscillation control in the final evaluation. Rhythmic Weight Shift test resembles virtual reality games, in which the subject is represented on the computer screen by an avatar. The aim of these movements was to keep the avatar between two parallel bars displayed on the computer screen during the test.

Balance training is an effective intervention to improve the oscillation of the gravity center (GC) and hence postural balance. A deficiency in this function may be associated with injury or falls in many populations, and is therefore considered a critical component of motor skills (27). In this context, virtual reality (VR) has had space in rehabilitation because it is a resource that can enhance visual biofeedback, being effective in improving posture and balance (2, 28).

The use of video games, especially Nintendo Wii ${ }^{\circledR}$ as rehabilitation tools is reported in other populations such as for older adults, as well as neurological (19) and orthopedic-trauma patients (29). Studies show that training with the Wii-rehabilitation has the potential to improve postural balance (18). Mhatre et al. (30) assessed adult balance in Parkinson's disease patients using a Wii-therapy protocol. These authors observed better results from postural balance measured by the Berg Balance Scale (BBS) (26). Bateni et al. (31) assessed balance in 17 older adults, divided into 3 groups: 1) Conventional therapy associated with Wii-rehabilitation, 2) Wiirehabilitation and 3) Conventional therapy. The results showed that the Wii rehabilitation improved balance, though the best results were observed in the group receiving conventional therapy associated to Wii-rehabilitation. A similar result was found in a study by Barcala et al. (2), who assessed balance in 12 hemiparetic patients submitted to balance training with Wii Fit ${ }^{\circledR}$ program, divided into two groups: 1) conventional physical therapy associated with Wiirehabilitation and 2) conventional physiotherapy.

The Wii Balance Board ${ }^{\circledR}$ (WBB) requires constant changes in standing posturefrom individuals, assessing their ability to control environmental stimulation using bodily changes (15). A study conducted with the WBB verified the functionality of the standing posture correction, meaning the ability to actively adjust abnormal standing posture. It assessed whether two people with multiple disabilities would be able to adjust their active standing posture according to stimulation. Data showed that both participants significantly increased the length of time in maintaining the correct standing posture, thus enabling the posture control system (32).

Despite scientific evidence on the improvement of postural balance through the use of Wii Fit Plus ${ }^{\circledR}$, our study showed no statistically significant differences in postural balance and quality of life before and after the exercise protocol. This finding can be explained by the bodily changes resulting from the changes that occur in a woman's body to allow normal and safe development of the fetus, as well as childbirth (33), particularly with respect to increased body weight and consequent anterior shifting of the gravity center (GC). These anatomical and physiological changes seem to be more consolidated in women in the third gestational trimester $(22,23)$, resulting in there being no effects of Nintendo Wii ${ }^{\circledR}$ exercises on postural balance of pregnant women in this gestation period.

The trunk of the pregnant women has greater variations in size and weight with asymmetrical 
distribution mainly in the anterior abdominal region (34), suggesting that the movements of this segment change over pregnancy. Thus, women in the third quarter would show a decrease in amplitude of trunk movement, making it more rigid and reducing the functional capacity of the trunk, as one of its functions is related to attenuation of postural fluctuations in order to maintain postural balance during performing functional activities such as walking and sit up (35).

Biomechanically, the weight increase in the anterior abdominal region promotes an increase in the anterior trunk flexion torque. In this situation, for preserve the anteroposterior stability in the standing position, the pregnant woman takes adaptive positions, such as increased lumbar lordosis that allows the pregnant woman to maintain a stable position, without major changes in the anteroposterior oscillation. This may explain why, under the conditions analyzed with open eyes, our results showed anteroposterior static stability unchanged in women during the perinatal period, corroborating the results of Opala-Berdzik et al. (36)

With regard to quality of life, no significant differences were observed before or after the intervention. This can be justified by complaints such as fatigue, sleepiness and lumbopelvic pain associated with emotional factors that limit the activity of pregnant women, and therefore, decrease the quality of life of this population (34).

Other reasons for such findings may be: reduced sample size which prevented the detection of differences before and after exercise and the absence of a control group. However, the chosen gestational age may have been the main justification. Moreover, considering that our patients were young and healthy pregnant women, the variables analyzed may not have had as much influence as with neurological patients, for example.

Despite the results not having shown significant differences, it was observed that the participants had mild improvement in balance and quality of life. This may suggest that games provide a high level of physical interaction and motivation, allowing the individual to create behavioral and motor strategies using stimulus provided by VR to facilitate their movement (18). This may be due to sensory information during each game, which are used by the postural control system to produce motor responses, restoring postural alignment (15).
Therefore, according to the findings, we reject the initial hypothesis of this study that the proposed exercise protocol would lead to improvement in variables related to postural balance and quality of life. However, although the study was conducted with a small sample size and only with pregnant women in the third trimester, the slight improvement trend in the analyzed variables identified in this preliminary study are important and warrant further research to examine the influence of the Nintendo WiiFit Plus ${ }^{\circledR}$ on postural balance and quality of life in pregnant women.

\section{Conclusion}

To this extent, this study is the first to analyze the influence of the Nintendo WiiFit Plus ${ }^{\circledR}$ on postural balance and quality of life of pregnant women, so it was not possible to compare the results obtained in this research with other scientific work for this population. Thus, our study opens the door to the use of Wii-rehabilitation in the population of pregnant women and its influence on postural balance during pregnancy.

The presence of a group composed only of women in the third gestational trimester is one of the limitations of this study. We therefore suggest that future studies evaluating the effect of Wii-rehabilitation on selected variables, incorporating a larger sample and including pregnant women in the first and second trimesters of pregnancy. From this it will be possible to evaluate the applicability of Nintendo Wii ${ }^{\circledR}$ as a complementary tool in postural balance training and for improving the quality of life of pregnant women.

\section{Acknowledgements}

We would like to thank the Pró-reitoria de Pesquisa da Universidade Federal do Rio Grande do Norte (PROPESQ) and the Coordenação de Aperfeiçoamento de Pessoal de Nível Superior (CAPES) for financial support.

\section{References}

1. Duarte M, Freitas SMSF. Revisão sobre posturografia baseada em plataforma de força para avaliação do equilíbrio. Rev Bras Fisioter. 2010;14(3):183-92. 
2. Barcala L, Colella F, Araujo MC, Salgado ASI, Oliveira CS. Análise do equilíbrio em pacientes hemiparéticos após o treino. Fisioter Mov. 2011;24(2):337-43.

3. Gaerlan MG, Alpert PT, Cross C, Louis M, Kowalski S. Postural balance in young adults: The role of visual, vestibular and somatosensory systems. J Am Acd Nurse Pr. 2012;14(6):375-81.

4. Aguiar L, Santos-Rocha R, Vieira F, Branco M, Andrade C, Veloso A. Comparison between overweight due to pregnancy and due to added weight to simulate body mass distribution in pregnancy. Gait Posture. 2015;42(4):511-7.

5. Gijon-Nogueron GA, Gavilan-diaz M, Valle-Funes V, Jimenez-Cebrian AM, Cervera-Marin JA, MoralesAsencio JM. Anthropometric foot changes during pregnancy: a pilot study. J Am Podiatr Med Assoc. 2013;103(4):314-21.

6. Aguiar L, Santos-Rocha R, Branco M, Vieira F, Veloso A. Biomechanical Model for Kinetic and Kinematic Description of Gait During Second Trimester of Pregnancy To Study the Effects of Biomechanical Load on the Musculoskeletal System. J Mech Med Biol. 2014;14(1):1450004.

7. Takeda K. A Kinesiological Analysis of the Standto-Sit during the Third Trimester. J Phys Ther Sci. 2012;24(7):621-4.

8. Mann L, Kleinpaul JF, Mota CB, Santos SG. Alterações biomecânicas durante o período gestacional: uma revisão. Motriz. 2010;16(3):730-41.

9. Okanishi N, Kito N, Akiyama M, Yamamoto M. Spinal curvature and characteristics of postural change in pregnant women. Acta Obstet Gynecol Scand. 2012;91(7):856-61.

10. Inanir A, Cakmak B, Hisim Y, Demirturk F. Evaluation of postural equilibrium and fall risk during pregnancy. Gait Posture. 2014;39(4):1122-5.

11. Cakmak B, Inanir A, Nacar MC, Filiz B. The effect of maternity support belts on postural balance in pregnancy. PM R. 2014;6(7):624-8.

12. McCrory JL, Chambers AJ, Daftary A, Redfern MS. Dynamic postural stability in pregnant fallers and non-fallers. BJOG. 2010;117(8):954-62.
13. Sousa VPS, Ribeiro SO, Aquino CMR, Viana ESR. Análise da relação entre dor lombar, idade gestacional e qualidade de vida durante a gravidez. Ter Man. 2011;9(46):769-73.

14. Augusto C, Vaghetti O, Botelho C. Ambientes virtuais de aprendizagem na educação física: uma revisão sobre a utilização de Exergames. Ciências \& Cognição. 2010;15(1):76-88.

15. Tavares CN, Carbonero FC, Finamore OS, Kós RS. Uso do Nintendo Wii para reabilitação de crianças com PC: Estudo de Caso. Rev Neurocienc. 2013;21(2):286-93.

16. Clark RA, Bryant AL, Pua Y, McCrory P, Bennell K, Hunt M. Validity and reliability of the Nintendo Wii Balance Board for assessment of standing balance. Gait Posture. 2010;31(3):307-10.

17. Bartlett HL, Ting LH, Bingham JT. Accuracy of force and center of pressure measures of the Wii Balance Board. Gait Posture. 2014;39(1):224-8.

18. Silva FD, Polese JC, Alvarenga LFC, Schuster RC. Efeitos da wiireabilitação na mobilidade de tronco de indivíduos com doença de Parkinson: Um estudo piloto. Rev Neurocienc. 2013;21(3):364-8.

19. Braga MMD, Nunes GS, Schutz GR, Menezes FS. Treinamento sensório-motor com Nintendo $\mathrm{Wii}^{\circledR}$ e disco proprioceptivo: efeitos sobre o equilíbrio de mulheres jovens saudáveis. $\mathrm{R}$ Bras Ci e Mov. 2012;20(3):37-45.

20. Kimura M, Silva JV. Índice de Qualidade de Vida de Ferrans e Powers. Rev Esc Enferm. 2009;43(Esp):1098-104.

21. Ribas SI, Guirro ECO. Análise da pressão plantar e do equilíbrio postural em diferentes fases da gestação. Rev Bras Fisioter. 2007;11(5):391-6.

22. Yoo H, Shin D, Song C. Changes in the spinal curvature, degree of pain, balance ability, and gait ability according to pregnancy period in pregnant and nonpregnant women. J Phys Ther Sci. 2015;27(1):279-84.

23. Moccellin A, Driusso P. Adjustments in static and dynamic postural control during pregnancy and their relationship with quality of life: A descriptive study. Fisioterapia. 2012;34(5):196-202. 
24. Butler EE, Colón I, Druzin ML, Rose J. Postural equilibrium during pregnancy: decreased stability with an increased reliance on visual cues. Am J Obstet Gynecol. 2006;195(4):1104-8.

25. Ersal T, McCrory JL, Sienko KH. Theoretical and Experimental Indicators of Falls during Pregnancy as Assessed by Postural Perturbations. Gait Posture. 2014;39:218-23.

26. Nagai M, Isida M, Saitoh J, Hirata Y, Natori H, Wada M. Characteristics of the control of standing posture during pregnancy. Neurosci Lett. 2009;462(2):130-4.

27. Gioftsidou A, Vernadakis N, Malliou P, Batzios S. Typical balance exercises or exergames for balance improvement ? J Back Musculoskelet Rehabil. 2013;26(3):299-305.

28. Abujaber S, Gillispie G, Marmon A, Zeni J. Validity of the Nintendo Wii Balance Board to assess weight bearing asymmetry during sit-to-stand and returnto-sit task. Gait Posture. 2015;41(2):676-82.

29. Park JH, Lee SH, Ko DS. The Effects of the Nintendo Wii Exercise Program on Chronic Work-related Low Back Pain in Industrial Workers. J Phys Ther Sci. 2013;25(8):985-8.

30. Mhatre PV, Vilares I, Stibb SM, Albert MV, Pickering L, Marciniak CM, et al. Wii Fit Balance Board playing improves balance and gait in Parkinson Disease. PM\&R. 2013;5(9):769-77.

31. Bateni H. Changes in balance in older adults based on use of physical therapy vs the wii fit gaming system: a preliminary study. Physiotherapy. 2012;98(3):211-6.
32. Shih $\mathrm{CH}$, Shih CT, Chu CL. Assisting people with multiple disabilities actively correct abnormal standing posture with a Nintendo Wii Balance Board through controlling environmental stimulation. Res Dev Disabil. 2010;31(4):936-42.

33. Ponnapula P, Boberg JS. Lower extremity changes experienced during pregnancy. J Foot Ankle Surg. 2010;49(5):452-8.

34. Opala-Berdzik A, Bacik B, Markiewicz A, CieślińskaŚwider J, Swider D, Sobota G, et al. Comparison of static postural stability in exercising and non-exercising women during the perinatal period. Med Sci Monit. 2014;20:1865-70.

35. Sawa R, Doi T, Asai T, Watanabe K, Taniguchi T, Ono R. Differences in trunk control between early and late pregnancy during gait. Gait Posture. 2015;42(4):455-9.

36. Błaszczyk JW, Opala-Berdzik A, Plewa M. Adaptive changes in spatiotemporal gait characteristics in women during pregnancy. Gait Posture. 2016;43:160-4.
Received in 05/27/2016 Recebido em 27/05/2016

Approved in 04/18/2017 Aprovado em 18/04/2017 